\title{
Genetic heterogeneity of autoimmune diabetes: age of presentation in adults is influenced by HLA DRB1 and DQB1 genotypes (UKPDS 43)
}

\author{
V. Horton ${ }^{1}$, I. Stratton ${ }^{1}$, G. F. Bottazzo ${ }^{2}$, M. Shattock ${ }^{2}$, I. Mackay ${ }^{3}$, P. Zimmet ${ }^{4}$, S. Manley ${ }^{1}$, R. Holman ${ }^{1}$, R. Turner ${ }^{1}$ \\ for the UK Prospective Diabetes Study (UKPDS) Group \\ ${ }^{1}$ Diabetes Research Laboratories, Radcliffe Infirmary, Oxford, United Kingdom \\ ${ }^{2}$ Department of Immunology, St. Bartholomew's and the Royal London School of Medicine and Dentistry, London, \\ United Kingdom \\ ${ }^{3}$ Department of Biochemistry and Molecular Biology, Monash University, Victoria, Australia \\ ${ }^{4}$ International Diabetes Institute, Royal Southern Memorial Hospital, Melbourne, Victoria, Australia
}

\section{Abstract}

Aims/hypothesis. Juvenile-onset, insulin-dependent diabetes is associated with islet cell antibodies and with specific "high-risk" HLA-DRB1 and HLA$D Q B 1$ genotypes. Patients with Type II (non-insulin-dependent) diabetes mellitus can have islet-related antibodies, but the genotypic associations at different ages of onset have not been evaluated. Our aim was to determine (i) the prevalence of $D R B 1$ and $D Q B 1$ genotypes in patients at diagnosis of Type II diabetes at different ages from 25 to 65 years compared with the general population, and (ii) whether the presence of islet cell antibodies (ICA) or glutamic acid decarboxylase antibodies (GADA) or both by age is associated with different $D R B 1$ and $D Q B 1$ genotypes.

Methods. The antibodies to islet cells and those to glutamic acid decarboxylase were measured in 1712 white Caucasian diabetic subjects at diagnosis of diabetes and they were genotyped for HLA $D R B 1 * 03$ and $D R B 1 * 04$ and the high-risk $D R B 1 * 04-D Q B 1 *$ 0302 haplotype. To assess over-representation of high-risk alleles for Type I (insulin-dependent) diabetes mellitus, the prevalence of high-risk alleles in diabetic patients was expressed relative to the prevalence of low-risk alleles, non-DR3/non-DR4, that provided a reference denominator in both the diabetic patients and in 200 non-diabetic control subjects. The prevalence of ICA or GADA or both in patients with different HLA genotypes was assessed in those diagnosed in four age groups, 25-34 years, 35-44 years, 45-54 years and 55-65 years.

Results. In Type II diabetic patients presenting at ages 25-34, 35-44 and 45-54 years, there was an increased prevalence of DR3/DR4 compared with the general population with approximately 6.5 -fold, 2.9 -fold, 2.1fold over-representation, respectively $(p<0.0001$, $<0.01,<0.05)$ but this was not found in those aged $55-65$ years old. In the group aged $25-34$ years, $32 \%$ of patients with ICA or GADA or both had $D R B 1 * 03 / D R B 1 * 04-D Q B 1 * 0302$ compared with $10 \%$ in those aged 55-65 years and expected $3 \%$ prevalence. Conversely, only $14 \%$ of those aged 25-34 years with antibodies had non-DR3/non-DR4, compared with $35 \%$ in those aged 55-65 years. There was thus pronounced age heterogeneity in $D R B 1$ and $D Q B 1$ predisposition to Type II diabetes. The antibodies displaced $D R B 1$ or $D Q B 1$ genotypes in the multivariate model for requiring insulin therapy by 6 years of follow-up.

Conclusion/hypothesis. The age of presentation of Type I diabetes in adulthood was in part dependent on the $D R B 1 / D Q B 1$ genotype. Islet cell antibodies and glutamic acid decarboxylase antibodies were strongly associated with $D R B 1 * 03 / D R B 1 * 04$ $D Q B 1^{*} 0302$ in early adulthood but showed little relation with specific HLA genotypes after the age of 55 years. [Diabetologia (1999) 42: 608-616]

Keywords Type I diabetes, Type II diabetes, HLA genotypes, $D Q B 1$ genotype, $D R B 1$ genotype.
Received: 27 April 1998 and in final revised form: 20 January 1999

Corresponding author: V. Horton, UK Prospective Diabetes Study Group, Diabetes Research Laboratories, Radcliffe Infirmary, Woodstock Road, Oxford, OX2 6HE, UK
Abbreviations: ICA, Islet cell antibodies; GADA, glutamic acid decarboxylase antibodies; IA-2, Protein tyrosine phosphate-2; VNTR, variable number tandem repeats; ARFLP, artificial restriction fragment length polymorphism. 
Type II (non-insulin-dependent) diabetes mellitus in adults usually has a distinct pathology from Type I (insulin-dependent) diabetes mellitus, which is an autoimmune disease directed against the insulin-secreting beta-cells of the pancreas [1]. Acute onset of diabetes occurs in children after $80-90 \%$ of beta-cells have been destroyed [2]. Of newly diagnosed patients with juvenile-onset Type I diabetes $95 \%$ have autoantibodies reactive to beta-cell antigens, which include cytoplasmic islet cell antibodies (ICA), glutamic acid decarboxylase antibodies (GADA) and the protein tyrosine phosphate-2 (IA-2) molecules [3, 4]. A proportion of Type II diabetic patients have ICA or GADA or both [5-7]. In the UK prospective diabetes study (UKPDS), we found that $33 \%$ of those aged 25-35 years had these autoantibodies, decreasing to $11 \%$ in those aged 55-65 years [8]. Although the younger patients with antibodies to islet cells are usually nonobese with pronounced hyperglycaemia and often progress rapidly to requiring insulin therapy, those presenting after 55 years of age usually have no remarkable clinical features and appear, at least at diagnosis, phenotypically similar to typical Type II diabetic patients [6, 8]. Nevertheless, those with antibodies are more likely to require insulin therapy than those without antibodies [8].

The genetic risk for Type I diabetes is strongly linked to the major histocompatibility complex (MHC) class II loci, $D R B 1$ and $D Q B 1$, on chromosome $6 \mathrm{p} 21$ [9]. The HLA DRB1 alleles $D R B 1{ }^{*} 03$ or $D R B 1{ }^{*} 04$ or both, termed DR3 and DR4, occur in more than $95 \%$ of Caucasian childhood-onset Type I diabetic patients, compared with $45-55 \%$ in the general population, with the heterozygote DR3/DR4 conferring the highest risk [10]. At the $D Q B 1$ locus, "non-Asp" alleles, which code for an amino acid other than aspartate at codon 57, confer an increased risk for Type I diabetes in white Caucasian populations [11]. The risk presented by the DR4 alleles is primarily attributable to an association in a haplotype with the $D Q B 1 * 0302$ allele, which codes for an alanine at codon 57 [12] and occurs on $95 \%$ of DR4 haplotypes associated with Type I diabetes and, in general, in more than $70 \%$ of juvenile-onset Type I diabetic patients [12]. The risk conferred by DR3 alleles is possibly associated with $D Q A 1$ alleles that encode the amino acid arginine at codon 52 such as $D Q A 1 * 0501$ [13]. Specific combinations of the HLA $D Q A 1$ and HLA $D Q B 1$ gene products may also be responsible for the increased risk associated with the DR3/ DR4 heterozygote $[13,14]$. Additional contributions to familial clustering of the disease from the insulin gene variable number tandem repeat (VNTR) and other loci have been identified $[15,16]$.

Type II diabetic patients with ICA can have a higher than expected prevalence of HLA DRB1 alleles usually associated with Type I diabetes $[17,18]$. Concentrating on the combinations of $D R B 1$ and $D Q B 1$ that can represent high-risk haplotypes in white Caucasian populations we have examined whether adult-onset patients, who at diagnosis did not require insulin therapy and were thought to have Type II diabetes, have an increased prevalence of HLA $D R B 1$ and $D Q B 1$ genotypes that predispose to autoimmune Type I diabetes. We also examined whether ICA or GADA or both occur with any specific HLA genotypes and whether the association of these islet-related antibodies with high-risk genotypes for Type I diabetes indicates Type II diabetic patients with an increased risk of requiring insulin after 6 years of follow-up.

\section{Methods}

Diabetic patients. Blood samples were obtained from a random selection of newly diagnosed white Caucasian patients from the UK prospective diabetes study (UKPDS), who had two fasting plasma glucose measurements $6.0 \mathrm{mmol} / 1$ with $94 \%$ having values more than $7.0 \mathrm{mmol} / \mathrm{l}$, the American Diabetes Association criteria for the diagnosis of diabetes [19]. The entry criteria excluded those with urine ketone bodies more than $3 \mathrm{mmol} / \mathrm{l}$ and thus excluded acute-onset Type I diabetes requiring prompt insulin therapy. We studied 1712 subjects ranging in age from 25 to 65 years, with means \pm SD for age $53 \pm 9$ years, fasting plasma glucose $11.8 \pm 3.8 \mathrm{mmol} / \mathrm{l}, \mathrm{HbA}_{1 \mathrm{c}}$ $9.1 \pm 2.3 \%$, body mass index $29 \pm 6 \mathrm{~kg} \mathrm{~m}^{-2}$ and median betacell function 36 (interquartile range 21 to 63 ) \% beta. We detected ICA in 137 subjects (8\%) and 209 (12\%) had GADA at diagnosis of diabetes. The UKPDS and the study of predisposing genes received ethical clearance. The study was done according to the Helsinki guidelines and all patients and control subjects gave their informed consent to the study, whose protocol was approved by the ethics committee of each centre.

Of the 1712 patients, when, after diet therapy alone fasting plasma glucose became more than $6.0 \mathrm{mmol} / \mathrm{l}, 702$ were randomly allocated in the UKPDS to insulin therapy and 1010 to diet or oral hypoglycaemic agents. Of these 1010 subjects, 113 $(11 \%)$ subsequently required insulin therapy within 6 years of entering the study as they developed hyperglycaemic symptoms or fasting plasma glucose more than $15.0 \mathrm{mmol} / \mathrm{l}$ when treated with maximum sulphonylureas and metformin therapy.

Normoglycaemic subjects. Blood samples were obtained from 200 healthy subjects with a similar age range to the UKPDS patients. They included 100 spouses or friends of UKPDS patients with a fasting plasma glucose concentration less than $6 \mathrm{mmol} / \mathrm{l}$ and 100 blood donors not known to have diabetes but in whom occult disease was not excluded.

Genotyping. DNA was extracted with a Nucleon kit (Scotlab, Strathclyde, Scotland) and amplified for genotyping of $D R B 1$ and $D Q B 1$ alleles. For a large-scale epidemiological study, we have used assays that identify all allele subtypes; $D R B 1 * 03$, termed DR3, and $D R B 1 * 04$, termed DR4, since specific genotyping of each allele is not feasible in large numbers. For $D Q B 1$ we have assessed DQbeta57 non-aspartate and aspartate alleles, which allows specific identification of the highrisk HLA $D R B 1 * 04-D Q B 1 * 0302$ haplotypes in those who are DR4 non-Asp/non-Asp in diabetic patients with autoantibodies and of the $D R B 1 * 03-D Q B 1 * 0201$ haplotype in those with DR3 non-Asp/non-Asp. In those with DR4 or DR3 with non-Asp/Asp, the haplotype could not be assigned. 
The DR3/DR4 alleles were detected by a method reported previously and presented briefly here [20]. The artificial restriction fragment length polymorphism (ARFLP)-PCR method for DR3/DR4 used the following primers: DR3ARFLP: $5^{\prime}$ CCG CTG CAC TGT GAA GCT CTC CAC AAC CCC GTA GTT GTG TCT GCA CTAG 3' (antisense); DR4.04: 5' CGG GTG CGG TTC CTG GAC AGA TAC TTC GAT $3^{\prime}$ (sense). The ARFLP PCR detects the known subtypes of DR3 and of DR4 alleles and the alleles that are in these subtypes, 5 and 22 respectively [21]. The ARFLP method for DR3 detects the high-risk alleles $D R B 1 * 0311, * 0302-0305$ (but not $* 0312$ ) but cannot distinguish heterozygous DR3/X from the homozygous DR3/DR3, which is a risk factor in childhood-onset Type I diabetes [10]. The DR4 method detects $D R B 1 * 0401-0422$, including the high-risk alleles 0401, 0402, 0405 that account for approximately $68 \%$ of the DR 4 alleles in the general population [22]. The DR4 alleles were detected by the introduction of a $\operatorname{Sau} 3 A I$ site into $D R B 1 * 04$ by replacing a $\mathrm{C}$ with a $\mathrm{G}$ in codon 32 . The DR3 alleles were detected by the introduction of a SpeI site into DR3ARFLP in codon 78. The pseudogene DRB7 was also detected by SpeI. To distinguish DR3 and DRB7, two Dde1 restriction sites (CTNAG), which were not present in any of the DR3 alleles, were found within DRB7: one at codons 51-52 and another at codons 58-59. With Sau3AI, a 186 base-pair (bp) fragment and a 27 bp fragment were diagnostic for DR4. With SpeI and DdeI 164 bp and 49 bp fragments were diagnostic for DR3 and $106 \mathrm{bp} ; 86 \mathrm{bp}$ and $21 \mathrm{bp}$ fragments were diagnostic for DRB7. Seven other alleles had one Dde1 site and for these, a $106 / 107$ bp product was observed. When both $D R B 1 * 03$ and $D R B 1 * 04$ were present, we referred to them as DR3/DR4.

The $D Q B 1$ alleles were detected by another method reported previously and presented briefly here [23]. The ARFLP method for the $D Q B 1$ gene used the following primers: DB130: 5' AGG GAT CCC CGC AGA GGA TTT CGT GTA CC 3'; P1: 5' TTC CTT CTG GCT GTT CCA GTA CTC GGA G 3'; P2: 5' TTC CTT CTG GCT GTT CCA GTA CTC GGA A $3{ }^{\prime}$. DQB1 contains 19 alleles, 10 of which code for aspartate at codon 57 and 9 of which code for an amino acid other than aspartate. A Hinf 1 restriction site (GANTC) was created in alleles encoding aspartate at 57 by changing the first base in codon 58 from a $\mathrm{G}$ to a $\mathrm{T}$ by constructing reverse primers that encoded an $\mathrm{A}$ instead of a $\mathrm{C}$ at this site. An additional nucleotide at the $3^{\prime}$ end of the primer allowed amplification and incorporation of the mismatch. All aspartate positive alleles, $D Q B 1 * 0301,0303,0401,0402,0503$, 0601, 0602, 0603, have GAC or GAT at codon 57 whereas non-aspartate alleles, $D Q B 1 * 0201,0302,0501,0502,0504$, 0604, 0605, have GTT (valine), AGC (serine), or GCC (alanine). Two primers were needed to detect all of these alleles. Primer $\mathrm{P} 1$ had $\mathrm{G}$ added to the $3^{\prime}$ end to amplify all alleles with $\mathrm{C}$ at the third base in codon 57 , and primer $\mathrm{P} 2$ had $\mathrm{A}$ added to amplify all codons with $\mathrm{T}$ in the third base with the sense primer DB130 binding all alleles. The alleles containing aspartic acid at position 57 are recognised by the digestion of a 199 bp product and $173 \mathrm{bp}$ and $26 \mathrm{bp}$ fragments.

Autoantibody measurements. At the first outpatient visit, when the diagnosis was confirmed, EDTA plasma was stored at $-20^{\circ} \mathrm{C}[8]$. We measured ICA with human pancreas sections by conventional indirect immunofluorescence [24], with a positive value defined as 5 or more Juvenile Diabetes Foundation Units (JDF-U). We measured GADA by a radioimmunoprecipitation assay, with a positive value defined as more than 20 $\mathrm{U} / 1$ [25]. Haemoglobin $\mathrm{A}_{1 \mathrm{c}}$ was measured in the coordinating laboratory by HPLC (Biorad, Hemel Hempstead, UK) with normal range $4.5-6.2 \%$.
Statistics. The prevalence of $D R B 1$ and $D Q B 1$ genotypes in the four age groups of diagnosis of diabetes, 25-34, 35-44, 45-54 and 55-65 years, was assessed relative to their prevalence in 200 control subjects. The overall distribution of $D R B 1$ and $D Q B 1$ genotypes in diabetic patients and control subjects was assessed by chi-squared test. The increase in prevalence of $D R B 1$ DR3/DR4 in some age groups, e.g. 25-35 years, indicated over-representation compared with control subjects. To quantify this over-representation, an assumption was made that the "low-risk" groups, i.e. DRB1 non-DR3/non-DR4 and $D Q B 1$ Asp/Asp, represented a stable "neutral" denominator that would be expected to have a similar prevalence in both diabetic patients and normal subjects. Thus the prevalence of the other genotypes was expressed relative to the prevalence to these "neutral" genotypes, using PROC CATMOD in SAS (SAS Institute, Carey, N.C., USA). The over-representation of each of the other alleles was expressed as a relative prevalence, with calculation of $95 \%$ confidence intervals. In view of the multiple comparisons this entailed, significant ratios were only taken to be relevant when the overall chi-squared distribution was also significant.

In each age group, the proportion of patients with each genotype who had GADA or ICA or both was assessed with the Mantel Haenzel test to determine if there was a trend within $D R B 1$ or $D Q B 1$ genotypes that was significantly different from that expected by chance. The same data were also expressed as the proportion of patients with antibodies who had different genotypes in each age group. The chi-squared test was used to determine whether at different ages these proportions were different from expected and for trend whether there was an age-related difference. The expected proportion of the normal population who would have each combination of $D R B 1$ and $D Q B 1$ genotypes was assessed by the product of the $D R B 1$ and $D Q B 1$ frequencies in the 200 control subjects.

The phenotypic variables at diagnosis of diabetes were expressed as mean (SD) of fasting plasma glucose, age, body mass index and mean (1 SD range) for beta-cell function. We used the homeostasis model assessment [26] to assess the beta-cell function. We assessed beta-cell function in relation to a reference group of 40 normoglycaemic subjects aged 18-25 years. Differences between the phenotypic variables for different genotypes was tested using analysis of variance or chi-squared test. Logistic regression analysis was used to determine which of age, sex, body mass index, $\mathrm{HbA}_{1 \mathrm{c}}$, GADA status, ICA status, DR3/4 and Asp/Nasp genotypes were univariate risk factors for progression to insulin within 6 years of diagnosis. These variables were used in a forward stepwise logistic regression to see which combination of factors best predicted the progression to insulin therapy within 6 years of diagnosis. Age, body mass index and $\mathrm{HbA}_{1 \mathrm{c}}$ were included as categorical variables.

All analyses were by SAS using the University of Oxford Computing Service UNIX machines.

\section{Results}

Prevalence of genotypes in Type II diabetic patients at different ages of diagnosis compared with control subjects. Table 1 shows the prevalence of DRB1 genotypes in diabetic patients by age of diagnosis, compared with control subjects. The overall distribution of $D R B 1$ genotypes differed from control subjects in the younger age groups, e.g. those aged 25-34 years, $35-44$ years and $45-54$ years. There was an increased 
Table 1. HLA $D R B 1$ genotypes in UKPDS patients diagnosed at different ages and in 200 control subjects

\begin{tabular}{|c|c|c|c|c|c|c|c|c|c|c|c|c|c|}
\hline & \multirow{2}{*}{$\begin{array}{l}\text { Control } \\
\text { Subjects } \\
n(\%)\end{array}$} & \multicolumn{3}{|c|}{25 to 35 years $(n=71)$} & \multicolumn{3}{|c|}{35 to 45 years $(n=216)$} & \multicolumn{3}{|c|}{45 to 55 years $(n=599)$} & \multicolumn{3}{|c|}{55 to 65 years $(n=826)$} \\
\hline & & $n(\%)$ & Ratio $^{\mathrm{b}}$ & $95 \% \mathrm{Cl}$ & $\overline{n(\%)}$ & Ratio $^{\mathrm{b}}$ & $95 \% \mathrm{Cl}$ & $\overline{n(\%)}$ & Ratio $^{\mathrm{b}}$ & $95 \% \mathrm{Cl}$ & $n(\%)$ & Ratio $^{\mathrm{b}}$ & $95 \%$ \\
\hline $\begin{array}{l}D R B 1 \\
\left(p \text { value }^{\mathrm{a}}\right)\end{array}$ & 200 & & $p<0.000$ & & & $p=0.00$ & & & $p=0.034$ & & & $p=0.54$ & \\
\hline $\mathrm{DR} 3 / \mathrm{DR} 4$ & $\begin{array}{l}12 \\
(6.0)\end{array}$ & $\begin{array}{l}15 \\
(21.1)\end{array}$ & 6.5 & $\begin{array}{l}2.5 \text { to } 16.6 \\
(p<0.0001)\end{array}$ & $\begin{array}{l}28 \\
(13.0)\end{array}$ & 2.9 & $\begin{array}{l}1.0 \text { to } 8.2 \\
(p=0.006)\end{array}$ & $\begin{array}{l}64 \\
(10.7)\end{array}$ & 2.01 & $\begin{array}{l}1.1 \text { to } 4.1 \\
(p=0.03)\end{array}$ & $\begin{array}{l}61 \\
(7.4)\end{array}$ & 1.2 & 0.8 to 1.8 \\
\hline DR4 & $\begin{array}{l}43 \\
(21.5)\end{array}$ & $\begin{array}{l}27 \\
(38.0)\end{array}$ & 3.3 & $\begin{array}{l}1.6 \text { to } 6.8 \\
(p=0.002)\end{array}$ & $\begin{array}{l}70 \\
(32.4)\end{array}$ & 2.0 & $\begin{array}{l}1.30 \text { to } 3.0 \\
(p=0.007)\end{array}$ & $\begin{array}{l}168 \\
(28.0)\end{array}$ & 1.5 & 1.00 to 2.33 & $\begin{array}{l}199 \\
(24.1)\end{array}$ & 1.1 & 0.7 to 1.7 \\
\hline DR3 & $\begin{array}{l}67 \\
(33.5)\end{array}$ & $\begin{array}{l}14 \\
(19.7)\end{array}$ & 1.18 & 0.5 to 2.4 & $\begin{array}{l}55 \\
(25.5)\end{array}$ & 1.0 & 0.6 to 1.7 & $\begin{array}{l}167 \\
(27.9)\end{array}$ & 1.0 & 0.7 to 1.4 & $\begin{array}{l}237 \\
(28.7)\end{array}$ & 0.9 & 0.6 to 1.2 \\
\hline $\begin{array}{l}\text { non-DR3/ } \\
\text { non-DR4 }\end{array}$ & $\begin{array}{l}78 \\
(39.0)\end{array}$ & $\begin{array}{l}15 \\
(21.1)\end{array}$ & $1.0^{\mathrm{c}}$ & & $\begin{array}{l}63 \\
(29.2)\end{array}$ & $1.0^{\mathrm{c}}$ & & $\begin{array}{l}200 \\
(33.3)\end{array}$ & $1.0^{\mathrm{c}}$ & & $\begin{array}{l}329 \\
(39.8)\end{array}$ & $1.0^{\mathrm{c}}$ & \\
\hline
\end{tabular}

${ }^{a}$ overall distribution different from control subjects

${ }^{\mathrm{b}}$ ratio, diabetic patients vs control subjects adjusting to prevalence of low-risk alleles, non-DR3/non-DR4 and Asp/Asp, re- spectively as reference groups, hence denominator of unity for these genotypes ${ }^{c}$

5.7). In the next three age groups, corresponding data were 1.8 (1.0 to 3.0), 1.7 (1.1 to 2.6) and 1.4 (0.9 to 2.0$)$, respectively.

In diabetic patients with DR3/DR4 aged 25-34 years, $12 / 15(80 \%)$ had $D R B 1 * 03 / D R B 1 * 04$ $D Q B 1 * 0302$, and this proportion decreased over the next three decades to $21 / 28$ (75\%), 36/64 (56\%) and $39 / 61(59 \%)$ respectively. For those with DR4 aged 25-34 years, i.e. DR4/DR4 or DR4/X, 12/27 (44\%) had $D R B 1 * 04-D Q B 1 * 0302$ with a similar proportion, $42-44 \%$ over the next three decades of age diagnosis. Thus in the younger patients there was greater overrepresentation of $D R B 1 * 03 / D R B 1 * 04-D Q B 1 * 0302$ than $D R B 1 * 04-D Q B 1 * 0302$. Since $D R B 1 * 03 / D R B 1$ $* 04-D Q B 1 * 0302$ probably accounts for half or less than half the DR3/DR4 in the general population (Fig.1), the over-representation of this haplotype could be twice as great as the risk ratios quoted above.

Prevalence of ICA or GADA or both in those with DRB1 genotypes and in specific haplotypes. Table 2 shows the proportion of patients with different genotypes at different ages who had either GADA or ICA, or specifically the GADA or ICA results alone. The trend to a greater proportion of younger, aged less than 45 years, than older patients, age 45 years or over, having antibodies was seen for all genotypes and for GADA and ICA when analysed separately.

DRB1 genotypes. In the three younger age groups studied, but not in the group aged 55-65 years, there was an association of antibodies with $D R B 1$ genotypes greater than was expected, with the highest proportion in those patients with DR3/DR4 $(p=0.039$, $p<0.001, p=0.003$, respectively).

$D Q B 1$ genotypes. The pattern was different from $D R B 1$, since in all age groups those with non-Asp/ non-Asp had a greater proportion of patients with islet-related antibodies than expected by chance. In

the group aged $25-34$ years [4\% (28/44) non-Asp/ value was 0.06 with relative to Asp/Asp an over-representation of NAsp/NAsp of 2.5 (95\% CI, 0.1 to prevalence of DR3/DR4 relative to non-DR3/nonDR4, as a reference group with risk ratios of $6.5,2.9$ plying over-representation of the DR3/DR4 genotype in these age groups. The prevalence of DR4 was increased, to a less pronounced degree, in the respectively $(p=0.002,0.007)$.

In each decade, the overall distribution of $D Q B 1$ genotypes in diabetic patients was not statistically significantly different from the control group, although in those aged 25-34 years the overall chi-squared $p$ 


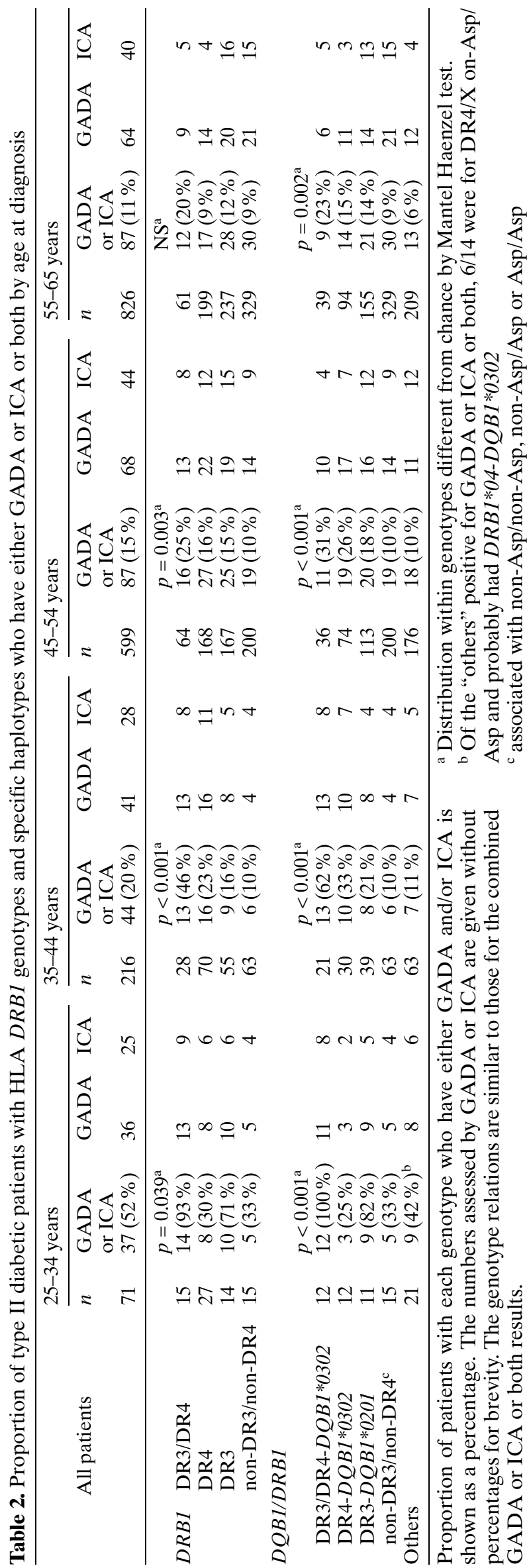

non-Asp had GADA or ICA compared with $42 \%$ (8/ 19) non-Asp/Asp] and $12 \%$ (1/18) for Asp/Asp $(p=0.005)$. In the group aged 55-65 years, a greater proportion of non-Asp/non-Asp genotypes were associated with antibodies than the other genotypes, $14 \%(57 / 399), 14 \%(21 / 301), 17 \%$ (9/126), respectively $(p=0.0031)$.

$D R B 1 / D Q B 1$ combinations. In the group aged 25-34 years, those with $D R B 1 * 03 / D R B 1 * 04$ $D Q B 1 * 0302$ had the highest proportion, $100 \%$, with islet-related antibodies, followed by $D R B 1 * 03$ $D Q B 1 * 0201$ with $82 \%$, implying that these are the major HLA allele contributors to Type I diabetes. In the group aged $55-65$ years, $D R B 1 * 03 / D R B 1 * 04$ $D Q B 1 * 0302, D R B 1 * 04-D Q B 1 * 0302$ and $D R B 1 * 03$ $D Q B 1 * 0201$ each were associated with antibodies to a greater extent than the $11 \%$ for all patients in that age group with a similar trend in the group aged $45-54$ years.

Distribution of DRB1 genotypes and specific haplotypes in patients positive for ICA or GADA or both. Table 3 and Figure 1 show the relative distribution of patients positive for ICA or GADA amongst the genotypes at the different ages. The greatest contributor was $D R B 1 * 03 / D R B 1 * 04-D Q B 1 * 0302$ in the youngest two age groups and non-DR3/non-DR4 in the oldest two age groups (chi-squared trend test for $D R B 1$ genotype with age $p=0.006$ ). Conversely, in the group aged 55-65 years, $D R B 1 * 03 / D R B 1 * 04$ $D Q B 1 * 0302$ was present in fewer patients, $10 \%$ compared with an expected $3 \%$ from the control group. The proportion of those with non-Asp/non-Asp who had GADA or ICA and who had DRBI*03/ $D R B 1 * 04-D Q B 1 * 0302$ decreased with age, being $43 \%, 39 \%, 18 \%, 16 \%$ in the four age groups, respectively. Whereas in the 25- to 34-year-old decade a large proportion of the non-Asp/non-Asp alleles were associated with $D R B 1 * 03 / D R B 1 * 04$ $D Q B 1 * 0302$, in the groups aged $45-65$ years the non-Asp/non-Asp alleles were more evenly distributed between $D R B 1$ alleles, including $D R B 1 * 04$ $D Q B 1 * 0302$ and $D R B 1 * 03-D Q B 1 * 0201$ and lowrisk non-DR3/non-DR4 alleles.

The characteristics, at diagnosis of diabetes, of patients with different genotypes and ICA or GADA or both. The patients with DR3/DR4 and islet-related antibodies presented at a younger age, mean 44 years compared with 53 years in those with non-DR3/nonDR4 (Table 4). The patients with non-Asp/non-Asp and positive for islet-related antibodies were similar in age to those with Asp/Asp (47.7 \pm 10.8 years vs $50.5 \pm 10.4$ years) but had a lower BMI, mean $26.0 \pm$ 5.1 compared with $29.7 \pm 7.3 \mathrm{kgm}^{-2}$ in those with Asp/Asp ( $p=0.007)$. There was also a graduation for insulin requirement by 6 years for non-Asp/non- 
Table 3. Proportion of (\%) of ICA or GADA or both positive patients who at different ages of diagnosis have different $D R B 1$ and specific haplotypes genotypes, with reference to the expected prevalence of genotypes from the control group

\begin{tabular}{|c|c|c|c|c|c|c|}
\hline & & GADA or & or both posi & patients $n(\%$ & & \\
\hline & Age groups (years) & $25-34$ & $35-44$ & $45-54$ & $55-65$ & \\
\hline Genotypes & $n$ & 37 & 44 & 87 & 87 & $\begin{array}{l}\text { Expected } \\
\text { prevalence from } \\
\text { control group }\end{array}$ \\
\hline & & & $\chi^{2} p=0.005$ & $\begin{array}{l}\chi^{2} \text { for trend } \\
p=0.006\end{array}$ & & \\
\hline & $\begin{array}{l}D R B 1 * 03 / D R B 1 * 04-D Q B 1 * 0302 \\
D R B 1 * 04-D Q B 1 * 0302 \\
D R B 1 * 03-D Q B 1 * 0201 \\
\text { non-DR3/non-DR } 4^{\mathrm{a}}\end{array}$ & $\begin{array}{r}12(32 \%) \\
3(8 \%) \\
9(24 \%) \\
5(14 \%)\end{array}$ & $\begin{array}{r}13(30 \%) \\
10(23 \%) \\
8(18 \%) \\
6(14 \%)\end{array}$ & $\begin{array}{l}11(13 \%) \\
19(22 \%) \\
20(23 \%) \\
19(22 \%)\end{array}$ & $\begin{array}{r}9(10 \%) \\
14(16 \%) \\
21(24 \%) \\
30(35 \%)\end{array}$ & $\begin{array}{r}3 \% \\
9 \% \\
15 \% \\
38 \%\end{array}$ \\
\hline
\end{tabular}

${ }^{a}$ associated with non-Asp/non-Asp, non-Asp/Asp or Asp/Asp

Table 4. Clinical characteristics at diagnosis of diabetes by genotype

\begin{tabular}{|c|c|c|c|c|c|c|c|c|c|}
\hline & \multirow{2}{*}{$\begin{array}{l}\text { All subjects } \\
\text { GADA \& } \\
\text { ICA positive }\end{array}$} & \multicolumn{5}{|c|}{ GADA or ICA or both positive } & \multirow{2}{*}{$\begin{array}{l}\mathrm{DR} 3 / \mathrm{DR} 4 \\
D Q B 1 * 0302\end{array}$} & \multicolumn{2}{|c|}{ GADA and ICA negative } \\
\hline & & $D R B 1$ & & & & ANOVA & & All subjects & ANOVA $^{\mathrm{a}}$ \\
\hline$n$ & 255 & 55 & 68 & 72 & 60 & & 45 & 1457 & \\
\hline Male $(\%)$ & $153(60 \%)$ & $37(67 \%)$ & $41(60 \%)$ & $43(60 \%)$ & $32(53 \%)$ & & $31(69 \%)$ & $820(56 \%)$ & NS \\
\hline $\begin{array}{l}\text { BMI }\left(\mathrm{kgm}^{-2}\right) \\
\text { fpg }\end{array}$ & $26.7(5.8)$ & $26.2(5.9)$ & $25.8(5.5)$ & $26.8(6.4)$ & $27.8(5.0)$ & & $25.1(4.1)$ & $29.4(5.4)$ & $3 \times 10^{-13}$ \\
\hline$\left(\mathrm{mmol} / \mathrm{l}^{-1}\right)$ & $12.6(4.1)$ & $13.1(4.2)$ & $12.6(4.0)$ & $12.6(4.0)$ & $12.7(4.1)$ & & $13.2(4.3)$ & $11.7(3.7)$ & 0.0005 \\
\hline $\begin{array}{l}\mathrm{HbA}_{1 \mathrm{c}}(\%) \\
\text { Beta-cell }\end{array}$ & $9.7(2.5)$ & $9.8(2.5)$ & $9.4(2.3)$ & $9.9(2.7)$ & $9.7(2.4)$ & & $9.8(2.5)$ & $9.0(2.2)$ & 0.0001 \\
\hline $\begin{array}{l}\text { function } \\
\text { (\% beta) }\end{array}$ & $29(13-63)$ & $24(10-58)$ & $29(14-61)$ & $31(14-68)$ & $29(14-64)$ & & $24(10-56)$ & $37(18-76)$ & $3 \times 10^{-7}$ \\
\hline GADA & & 93 & 76 & 86 & 84 & & 88 & & \\
\hline$(\mathrm{U} / 1)^{\mathrm{c}}$ & & $(72-110)$ & $(50-102)$ & $(53-104)$ & $(37-98)$ & & $(74-108)$ & & \\
\hline $\mathrm{ICA}(\mathrm{U} / \mathrm{l})^{\mathrm{c}}$ & & $32(18-80)$ & $56(15-80)$ & $47(14-80)$ & $26(14-49)$ & & $32(24-80)$ & & \\
\hline
\end{tabular}

Data shown are mean (SD) or geometric mean (1 SD range)

${ }^{a}$ compared with all subjects with GADA or ICA or both positive

Asp, non-Asp/Asp, Asp/Asp, 49\%, 35\% and 14\%, respectively (chi-squared for trend $p=0.008$ ). The antibody concentrations between genotypes did not differ.

Risk factors for insulin requirement. There was a greater likelihood for insulin requirement by the end of 6 years of follow-up in those with high risk $D R B 1$ or $D Q B 1(p=0.03)$ genotypes (Table 4$)$. Table 5 shows the univariate risk factors, as published previously [8]. Multivariate analysis shows that the genotype
${ }^{\mathrm{b}} p$ value for comparison with all other combinations ${ }^{c}$ level in subjects with positive antibodies (GADA > $20 \mathrm{U} / \mathrm{l}$, $\mathrm{ICA}>5 \mathrm{U} / \mathrm{l})$

relation was displaced by the presence of ICA and GADA and taking these into account there was no additional contribution from the genotype (Table 5).

\section{Discussion}

Assuming the presence of beta-cell autoantibodies implies an autoimmune basis for the occurrence of diabetes, this study shows that the HLA genotype is a major factor in determining the age at which autoim- 
Table 5. Logistic regression: stepwise model for progression to requiring insulin therapy by 6 years of follow-up

A Univariate analysis

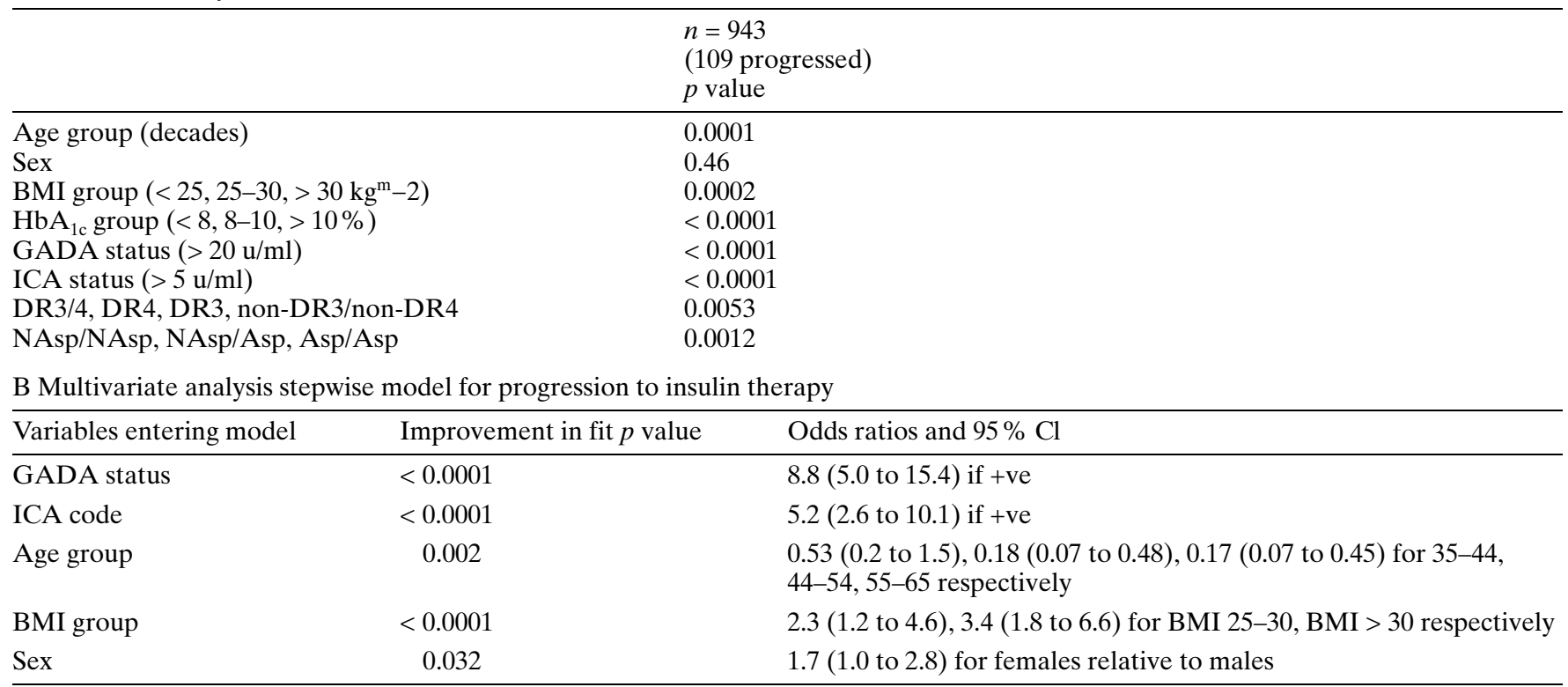

$\mathrm{N}=$ non

mune diabetes presents to physicians. In the age group 25-34 years, and to a lesser extent in the group aged 35-44 years, Type II diabetic patients with $D R B 1 * 03 / D R B 1 * 04-D Q B 1 * 0302$ were over-represented compared with the general population, indicating a substantial number of Type I diabetic patients had been "imported" into the Type II diabetic category with a similar but less pronounced effect for $D R B 1 * 04-D Q B 1 * 0302$. In the group aged 55-65 years, DR3/DR4 and DR4 were not over-represented compared with the general population.

The HLA Class II locus in childhood Type I diabetes accounts for $32 \%$ of susceptibility in British white Caucasian, multiplex families with the major contribution from $D R B 1 * 04-D Q B 1 * 0302[9,27]$. This study shows that $D R B 1 * 03 / D R B 1 * 04-D Q B 1 *$ 0302 also provide the major contribution to the Type I diabetes in early adulthood presenting as Type II diabetes but that the high-risk haplotypes contribute less to autoimmune diabetes presenting as Type II diabetes in older adults. Thus the prevalence of $D R B 1 * 03 / D R B 1 * 04-D Q B 1 * 0302$ in those with antibodies over the four decades decreased: $32 \%, 30 \%, 13 \%$ and $10 \%$, compared with $3 \%$ in published control population data [10]. This extends the observation of genotypes in classical childhoodonset Type I diabetes, where those after the age of 17 have fewer high-risk alleles than in younger patients, whereas those aged less than 5 years predominantly have $D R B 1 * 03 / D R B 1 * 04-D R B 1 * 0302 \quad[28$, $29]$. In the older age groups, over 45 years at diagnosis of diabetes - the antibodies were associated to a greater extent with non-DR3/non-DR4 than in the younger age groups. A greater than expected associ- ation with non-DR3/non-DR4 genotypes has also been reported in childhood-onset Type I diabetes [30].

In a univariate logistic regression analysis, the high-risk $D R B 1$ or $D Q B 1$ genotypes were risk factors for requirement of insulin therapy, although this was displaced by the presence of antibodies in a multivariate analysis, suggesting the HLA genotypic background may not have a major role in the severity of the disease, once autoimmunity has been established. The lack of association of genotype with the level of GADA or ICA may reflect that the antibodies are indicative of an autoimmune process but are not themselves pathogenic. The degree of glucose control was similar across genotypes at presentation of diabetes, since the degree of hyperglycaemia that induced symptoms is the reason for clinical diagnosis of diabetes in most patients.

The substantial proportion of patients with antibodies in the older age groups, which had none of the high-risk HLA alleles studied, may reflect multifactorial pathogenesis, including the possibility that their late age of onset of diabetes was in part because of a low genetic risk for development of an autoimmune type of diabetes, with reduced predisposition to a putative virus infection [31] or other extraneous beta-cell insults. High-risk HLA alleles are neither necessary nor sufficient for disease expression and, even in childhood-onset Type I diabetes, $5 \%$ of patients lack high-risk HLA alleles [10]. In Asian populations, in which the HLA alleles that confer susceptibility in Caucasian diabetic patients have a low frequency, the age of onset of insulin-dependent diabetes is in late teenage or early adulthood compared 
with a younger age of onset in white Caucasians [32]. It has been theorised that there is a hierarchy of susceptibility alleles and that Type I diabetes can occur when certain alleles of intermediate risk are present in an environmental and genotypic background suitable for Type I diabetes to develop [33], and this is supported by additional studies [34, 35]. Further typing at the $D R B 1$ and $D Q B 1$ loci could be undertaken to show whether the non high-risk alleles are intermediate in risk or associated with protection. At the $D R B 1$ locus, alleles $D R B 1 * 0403, D R B 1 * 0406$ and $D R B 1 * 0408$ are associated with the highest risk and the rest are intermediate between the two [35, 37]. Typing to show the amino acid at codon 57 would be informative as risk in non-Asp alleles is strongest with alanine, then valine and finally serine [35]. The Asp allele $D Q B 1^{*} 0602$ is associated with dominant protection in childhood-onset patients even when ICA and GADA are present [14]. Non-HLA genetic determinants are well known, including the insulin gene class 1 VNTR and other predisposing genotypes yet to be fully identified $[9,15,36]$. A more detailed analysis of HLA DR and DQ, the VNTR of the insulin gene and other genes will allow a more completed understanding of the interplay between genetic and environmental influence on the age of onset of Type I diabetes $[16,36]$.

The presence of GADA or ICA in Type II diabetes implicates an autoimmune process, although it is associated with T-cells, which induce beta-cell destruction. Autoantibodies are not always indicative of progressive autoimmune destruction, since patients with autoimmune polyendocrine disease with autoantibodies to beta-cell antigens do not always progress to diabetes $[38,39]$.

In theory, short-term autoimmune antibodies can arise from tissue destruction, e.g. sub-acute thyroiditis or mumps, and an alternative suggestion would be that in some patients antibodies are stimulated by non-autoimmune beta-cell destruction [40]. There are, however, no known models of long-term tissue destruction leading to persistence of antibodies. In chronic calciferous pancreatitis in India, which is not thought to be an autoimmune disease, some studies found no islet cell antibodies [41] but other antibodies at a low frequency [42]. It is likely that the antibodies measured in our study reflect autoimmune disease, particularly as GADA or ICA or both are major risk factors for requiring insulin therapy in patients with Type II diabetes [8].

This study suggests that the $D R B 1$ and $D Q B 1$ genotypes are major risk factors for autoimmune diabetes presenting in adult life, with the age of onset being in part determined by the genotype. Once autoimmune diabetes has, however, presented as Type II diabetes, the predisposing genotype was not associated with a greater risk of requiring insulin therapy in the subsequent 6 years.
Acknowledgements. We are grateful to the Juvenile Diabetes Foundation International and the Alan and Babette Sainsbury Trust for grants for genotyping; to the Wellcome Trust for a grant for assaying antibodies; to the Medical Research Council UK, British Diabetic Association, National Institute for Diabetes, Digestive and Kidney Disease and National Institute of Eye Disease, National Institutes of Health, Department of Health, British Heart Foundation, Bayer, Bristol Myers Squibb, Novo Nordisk, Lilly and Lipha for grants to the UKPDS; to Professor J. Todd for advice on the manuscript; to Dr. Y.-M. D. Lo and Dr. P. Patel for assistance with developing the genotyping to Dr. K. Welsh for the DNA from 100 blood donors; and to Mrs K. Waring for typing the manuscript and tables.

\section{References}

1. Bottazzo GF (1993) On the honey disease. A dialogue with Socrates. Diabetes 42: 778-800

2. Rahier J, Goebbels RM, Henquin JC (1983) Cellular composition of the human diabetic pancreas. Diabetologia 24: 366-371

3. Bonifacio E, Genovese S, Braghi S et al. (1995) Islet autoantibody markers in IDDM: risk assessment strategies yielding high sensitivity. Diabetologia 38: 816-822

4. Verge CF, Howard NJ, Rowley MJ et al. (1994) Antiglutamate decarboxylase and other antibodies at the onset of childhood IDDM: a population-based study. Diabetologia 37: $1113-1120$

5. Groop LC, Bottazzo GF, Doniach D (1986) Islet cell antibodies identify latent type 1 diabetes in patients aged 35-37 years at diagnosis. Diabetes 35: 237-241

6. Zimmet PZ, Tuomi T, Mackay IR et al. (1994) Latent autoimmune diabetes mellitus in adults (LADA): the role of antibodies to glutamic acid decarboxylase in diagnosis and prediction of insulin dependency. Diabet Med 11:299-303

7. Tuomi T, Groop LC, Zimmet PZ, Rowley MJ, Knowles W, Mackay IR (1993) Antibodies to glutamic acid decarboxylase reveal latent autoimmune diabetes mellitus in adults with a non-insulin-dependent onset of disease. Diabetes 42: $359-362$

8. UKPDS Group (1997) UKPDS 25: Clinical value of ICA and GADA in predicting insulin requirement in patients with newly diagnosed NIDDM at different ages. Lancet 350: $1288-1293$

9. Davies JL, Kawaguichi Y, Bennett ST et al. (1994) A genome-wide search for human type 1 diabetes susceptibility genes. Nature 371: 130-136

10. Thomson G, Robinson WP, Kuhner MK et al. (1988) Genetic heterogeneity: modes of inheritance and risk estimates for a joint study of Caucasians with insulin-dependent diabetes mellitus. Am J Hum Genet 43: 799-816

11. Todd JA, Bell JI, McDevitt HO (1987) HLA-DQ $\beta$ gene contributes to susceptibility and resistance to insulin-dependent diabetes mellitus. Nature 329: 599-604

12. Nepom BS, Palmer J, Kim SJ, Hansen JA, Holbeck SL, Nepom GT (1986) Specific genomic markers for the HLADQ subregion discriminate between DR4 + insulin-dependent diabetes mellitus and DR4 + seropositive juvenile rheumatoid arthritis. J Exp Med 164: 345-350

13. Kahlil I, Deschamps I, Lepage V, Al-Daccak R, Degos L, Hors J (1992) Dose effect of cis- and trans-encoded HLADQab heterodimers in IDDM susceptibility. Diabetes 41: 378-384

14. Pugliese A, Gianini R, Moromisato R et al. (1995) HLADQB $1 * 0602$ is associated with dominant protection from 
diabetes even among islet cell antibody-positive first-degree relatives of patients with IDDM. Diabetes 44: 608-613

15. Lucassen AM, Julier C, Beressi JP et al. (1993) Susceptibility to insulin dependent diabetes mellitus maps to a $4.1 \mathrm{~kb}$ segment of DNA spanning the insulin gene and associated VNTR. Nat Genet 4: 305-310

16. Nistico L, Buzzetti R, Pritchard LE et al. (1996) The CTLA-4 gene region of chromosome $2 \mathrm{q} 33$ is linked to, and associated with, Type 1 diabetes. Hum Mol Gen 5: 1075-1080

17. Groop L, Miettinen A, Groop P-H, Meri S, Koskimies, Bottazzo GF (1988) Organ-specific autoimmunity and HLA-DR antigens as markers for B-cell destruction in patients with Type 2 diabetes. Diabetes 37: 99-103

18. Gleichmann H, Zorcher B, Greulich B et al. (1984) Correlation of islet cell antibodies and HLA-DR phenotypes with diabetes mellitus in adults. Diabetologia 27: 90-92

19. UKPDS Group (1991) UK Prospective Diabetes Study VIII: Study design, progress and performance. Diabetologia 34: 877-890

20. Horton VA, Bunce M, Davies DR, Turner RC, Lo YM (1995) HLA typing for DR3 and DR4 using artificial restriction fragment length polymorphism-PCR from DNA using archival materials. J Clin Pathol 48: 33-36

21. Marsh SG, Bodmer JG (1995) HLA class II region nucleotide sequences, 1995. Tissue Antigens 46: 258-280

22. Doherty DG, Vaughan RW, Donaldson PT, Mowat AP (1992) HLA, DQA, DQB and DRB genotyping by oligonucleotide analysis: distribution of alleles and haplotypes in British caucasoids. Hum Immunol 34: 53-63

23. Patel P, Lo Y-MD, Bell JI, Wainscoat JS (1992) Detection of susceptibility alleles to insulin-dependent diabetes mellitus at the DQB1 locus by artificial PCR RFLP. Immunogenetics 36: 264-265

24. Bonifacio E, Bingley PJ, Shattock M et al. (1990) Quantification of islet-cell antibodies and prediction of insulin dependent diabetes. Lancet 335: 147-149

25. Rowley MJ, Mackay IR, Chen QY, Knowles WJ, Zimmet PZ (1992) Antibodies to glutamic acid decarboxylase discriminate major types of diabetes mellitus. Diabetes 41: 548-551

26. Matthews DR, Hosker JP, Rudenski AS, Naylor BA, Treacher DF, Turner RC (1985) Homeostasis model assessment: insulin resistance and $\beta$-cell function from fasting plasma glucose and insulin concentrations in man. Diabetologia 28: 412-419

27. Todd JA (1995) Genetic analysis of type 1 diabetes using a whole genome approach. Proc Natl Acad Sci USA 92: 8560-8565

28. Caillat-Zucman S, Garchon H, Timsit J et al. (1992) Agedependent HLA genetic heterogeneity of Type 1 insulindependent diabetes mellitus. J Clin Invest 90: 2242-2250

29. Karjalainen J, Salmela P, Ilonen J, Surcel HM, Knip M (1989) A comparison of childhood and adult type 1 diabetes mellitus. N Engl J Med 320: 881-886
30. Dubois-Laforgue D, Timsit J, Djilali-Saiah I, Bitard C, Caillet-Fulman S (1997) Insulin dependent diabetes mellitus in nonDR3/nonDR4 subjects. Hum Immunol 57: 107-109

31. Oldstone MBA, Nerenberg M, Southern P, Price J, Lewicki H (1991) Virus infection triggers insulin-dependent diabetes mellitus in a transgenic model: role of anti-self (virus) immune response. Cell 65: 319-332

32. Zimmet PZ, Rowley MJ, Mackay IR et al. (1993) The ethnic distribution of antibodies to glutamic acid decarboxylase: presence and levels in insulin-dependent diabetes mellitus in Europid and Asian subjects. J Diabetes Complications $7: 1-7$

33. Nepom GT (1990) A unified hypothesis for the complex interactions of HLA associations with IDDM. Diabetes 39: 1153-1157

34. Cucca F, Todd JA (1996) HLA susceptibility to type 1 diabetes: methods and mechanisms. In: Browning $\mathrm{MJ}$, McMichael AJ (eds) HLA and MHC: genes, molecules and function. BIOS Scientific Publishers, Oxford, pp 383-406

35. She JX (1996) Susceptibility to type I diabetes: HLA-DQ and DR revisted. Immunol Today 17: 323-329

36. Bennett ST, Lucassen AM, Gough SCL et al. (1995) Susceptibility to human type 1 diabetes at IDDM2 is determined by tandem repeat variation at the insulin gene minisatellite locus. Nat Genet 9: 284-292

37. van der Auwera B, van Waeyenberge C, Schuit F et al. (1995) DRB1*0403 protects against IDDM in Caucasians with the High-Risk heterozygous DQA*0301DQB1*0302/DQA1*0501-DQB1*0201 genotype. The Belgian Diabetes Registry. Diabetes 44: 527-530

38. Genovese S, Bonifacio E, McNally JM et al. (1992) Distinct cytoplasmic islet cell antibodies with different risks for type 1 (insulin-dependent) diabetes mellitus. Diabetologia 35: 385-388

39. Bjork E, Velloso L, Kampe O, Karlsson FA (1994) GAD autoantibodies in IDDM, stiff-man syndrome and autoimmune polyendocrine syndrome type 1 recognize different epitopes. Diabetes 43: 161-165

40. Ikenoue H, Okamura K, Kuroda T, Sato K, Yoshinari M, Fujishima M (1988) Thyroid amyloidosis with recurrent subacute thyroiditis-like syndrome. J Clin Endocrinol Metab 67: 41-45

41. Sanjeevi CB, Kanugo A, Samal KC, Tripathy BB, Lernmark Å, Falorni A (1996) GAD ${ }^{65}$ antibodies in insulin-dependent diabetes (IDDM), malnutrition-related diabetes (MRDM) and non-insulin dependent diabetes (NIDDM) patients from eastern India. Diabetologia 39:S301, A81

42. Mohan V, Deepa R, Bhatia E et al. (1998) Antibodies to pancreatic islet cell antigens in diabetes seen in southern India with particular reference to fibrocalculous pancreatic diabetes. Diabet Med 15: 156-159 